Table 2 Distribution of thyroid stimulating hormone (TSH) values among boys and girls aged 6-9 years

\begin{tabular}{lccc}
\hline TSH $(m U / l)$ & Boys & Girls & Total \\
\hline$<0.9$ & 1 & 1 & 2 \\
$1 \cdot 0-2 \cdot 9$ & 68 & 50 & 118 \\
$3 \cdot 0-4 \cdot 9$ & 66 & 44 & 110 \\
$5 \cdot 0-6 \cdot 9$ & 15 & 17 & 32 \\
$7 \cdot 0-8 \cdot 9$ & 5 & 5 & 10 \\
$>9.0$ & 0 & 2 & 2 \\
\hline
\end{tabular}

and the patella showed multicentre ossification sites suggesting that hypothyroidism dated from age 5 or 6 years. The thyroid scan showed low iodine uptake. Of the 11 children with TSH values greater than $7.0 \mathrm{mU} / 1,1$ with a TSH value of $7.2 \mathrm{mU} / 1$ and T4 value of $126 \mathrm{nmol} / \mathrm{l}$ also had an indifferent human growth hormone response $(9.5 \mathrm{mU} / \mathrm{l})$ to insulin hypoglycaemia. Another child had a $\mathbf{T}_{4}$ value of $76 \mathrm{nmol} / \mathrm{l}$ but like the remaining 9 was otherwise clinically normal. The TSH concentrations in boys and girls were similar (mean (SD) $3.38(1.44) \mathrm{mU} / 1$ and $3.63(1.70) \mathrm{mU} / 1$ respectively). There was no significant correlation with sex, age, height, or bone age.

\section{Discussion}

The diagnosis of only 1 child with previously undiagnosed hypothyroidism in a very large epidemiological study of 6-9 year old children refutes the belief that hypothyroidism is the commonest cause of short stature in this age group in a population with well developed health services. It does, however, prove that onset and progress may be so insidious that hypothyroidism may escape notice especially when it occurs after the routine examination at school entry that includes the recording of height in centiles. It is likely given the knowledge from neonatal screening that about 1 baby in 4000 has congenital hypothyroidism, and that some children in the 48221 screened were receiving thyroxine and had heights above the first centile.

Although associations between coeliac disease and diabetes mellitus and between diabetes and auto immune thyroiditis are recognised, we do not know of any published reports linking coeliac disease and hypothyroidism. The finding of borderline low values for T4 in the 2 coeliac children in this study was not associated with TSH abnormality and in these cases this excludes primary hypothyroidism but not perhaps some disturbance of thyroid binding globulin.

\section{References}

1 Zachmann M. Diagnosis of treatable types of short and tall stature. In: Barltrop D, ed. Paediatrics and growth. (Unigate Paediatric Workshop No. 5). Fellowship of Postgraduate Medicine, 1978: 121-32.

2 Vimpani GV, Vimpani AF, Lidgard GP, Cameron EHD, Farquhar JW. Prevalence of severe growth hormone deficiency. $\mathrm{Br}$ Med J 1977; ii: 427-30.

3 Vimpani GV, Vimpani AF, Pocock SJ, Farquhar JW. Differences in physical characteristics, perinatal histories and social backgrounds between children with growth hormone deficiency and constitutional short stature. Arch Dis Child 1981 ; 56: 922-8.

Correspondence to Professor J W Farquhar, Department of Child Life and Health, University of Edinburgh, 17 Hatton Place, Edinburgh EH9 1 UW.

Received 18 May 1983

\title{
Human chorionic gonadotrophin secreting pineal germinoma and precocious puberty
}

\author{
S R AHMED, S M SHALET, D A PRICE, AND D PEARSON
}

Departments of Endocrinology and Radiotherapy, Christie Hospital, Manchester and Department of Paediatrics, Royal Manchester Children's Hospital

SUMMARY A $10 \frac{1}{2}$ year old boy presented with raised intracranial pressure and precocious puberty caused by a human chorionic gonadotrophin (HCG) secreting pineal germinoma. After craniospinal irradiation he improved clinically and his HCG concentration fell to an undetectable value. Two years later he remains well. Pineal germinomas are highly radiosensitive obviating the need for difficult surgery associated with high mortality.
Precocious puberty in boys may be caused by pineal tumours. Premature sexual development has been variously attributed to activation of hypothalamic centres initiating pubertal development, tumour involvement of hypothalamic centres that normally inhibit sexual development, loss of a pineal antigonadotrophic factor, or the production of a gonadotrophin by the tumour. Secretion of human chorionic gonadotrophin (HCG) by pineal tumours has been reported in 5 patients, ${ }^{1-4} 2$ of whom 
presented with precocious puberty. We studied a boy with precocious puberty caused by an HCG secreting pineal germinoma and describe the pubertal endocrine changes that accompanied successful treatment.

\section{Case report}

A $10 \frac{1}{2}$ year old boy presented in January 1981 with a 2 week history of headache and vomiting followed by 2 grand mal fits. His parents had noticed genital development, the appearance of pubic and facial hair, acne, and a hoarse voice several months before. When admitted to hospital he had papilloedema, limitation of upward gaze, and neck stiffness. His standing height was $146 \cdot 2 \mathrm{~cm}$ ( 75 th centile) and his pubertal development was well advanced with genitalia stage $3^{5}$, pubic hair stage $4^{5}$ and testes $3 \mathrm{ml}$ bilaterally. Computed axial tomography scan showed obstructive hydrocephalus and a pineal tumour that enhanced with contrast. At operation the tumour could not be excised but a biopsy specimen was taken and a germinoma diagnosed. He was referred for radiotherapy at which time his bone age was 13.6 years $^{6}$ and biochemical investigations showed a serum $\beta$ HCG concentration 1750 IU/l (normal $<10 \mathrm{IU} / \mathrm{l})$, testosterone value $28.4 \mathrm{nmol} / \mathrm{l}(98.46$ $\mathrm{ng} / \mathrm{ml}$ ) (normal adult male range $10-30 \mathrm{nmol} / \mathrm{l}$ (34.67-104.01 ng/ml)), and an $\alpha$ fetoprotein concentration of $84 \mathrm{U} / \mathrm{ml}$ (normal $<12 \mathrm{U} / \mathrm{ml}$ ). Radiotherapy was 30 Gy (3000 rad) (20 treatments over 25 days) to the whole central nervous system and a further $15 \mathrm{~Gy}$ (1500 rad) (10 treatments over 11 days) to the pineal region. By the time radiotherapy had been completed the serum $\beta$ HCG concentration had fallen to $<1 \mathrm{IU} / \mathrm{l}$, the serum testosterone to $1.7 \mathrm{nmol} / 1(5.98 \mathrm{ng} / \mathrm{ml})$, and serum $\alpha$ fetoprotein to $<12 \mathrm{U} / \mathrm{ml}$. There was resolution of the clinical signs of the tumour with normal optic discs and ocular movements. A repeat computerised axial tomography scan showed no evidence of the pineal tumour. A combined insulin tolerance test, thyrotrophin releasing hormone test, and gonadotrophin releasing hormone test showed no evidence of anterior pituitary hormonal deficiency. The basal serum prolactin concentration was $199 \mathrm{mU} / \mathrm{l}$ (normal $350 \mathrm{mU} / \mathrm{l})$ and there was no clinical evidence of diabetes insipidus.

In just under 2 years since radiotherapy his bone age has advanced 2.5 years and he has grown $10 \cdot 1$ $\mathrm{cm}$ so that his current standing height is $156.3 \mathrm{~cm}$. There has been a gradual increase in testicular size from 3 to $8 \mathrm{ml}$ and further enlargement of the penis (genitalia stage 4). Associated with pubertal development there have been appropriate increases in serum follicle stimulating hormone, luteinising hormone, and testosterone concentrations (Figure).

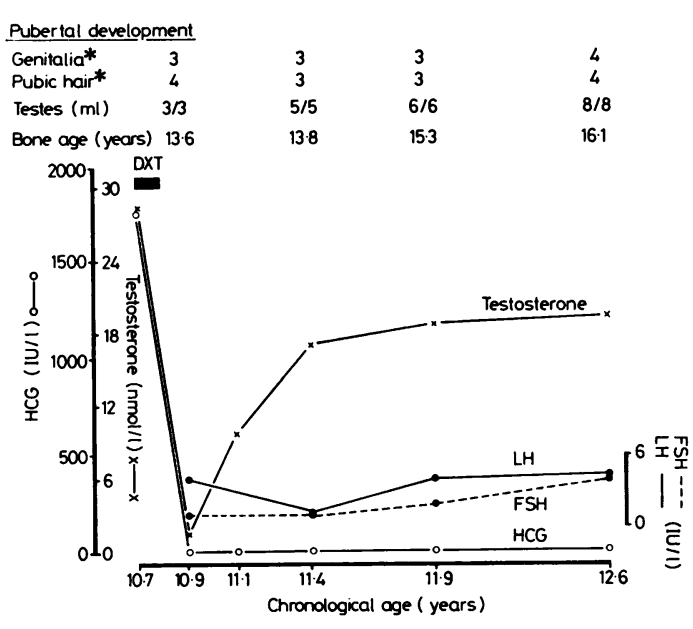

Figure Changes in human chorionic gonadotrophin $(H C G)$, testosterone, and gonadotrophin concentrations after treatment and in relation to chronological age, bone age, and pubertal development.

*According to Tanner. 5

DXT $=$ radiotherapy $; \quad$ FSH $=$ follicle stimulating hormone; $\mathbf{L H}$ = luteinising hormone.

Ccnversion: SI to traditional units - testosterone $1 \mathrm{nmol} / 1 \approx$ $3.47 \mathrm{ng} / \mathrm{ml}$.

He remains well with no clinical or radiologice evidence of recurrence of tumour. The $\beta \mathrm{HCG}$ and $\alpha$ fetoprotein concentrations remain undetectable. Anterior pituitary function remains intact except for blunting of the growth hormone responses to arginine stimulation and insulin hypoglycaemia.

\section{Discussion}

Our patient presented with features of raised intracranial pressure, Parinaud's syndrome, and precocious puberty. The tall stature, advanced bone age, pubic hair, and genital development were caused by the raised testosterone concentration. HCG has structural and functional similarities to luteinising hormone and excessive amounts of HCG $\bigcirc$ produced by the pineal germinoma resulted in stimulation of the Leydig cells of the testis and a testosterone concentration at the upper limit of the normal range for adult males. The small size of the of testes compared with the rest of pubertal develop- N ment suggested that sexual precocity was independent $N$ of activation of the hypothalamic pituitary gonadotrophin axis. Indeed patients with ectopic HCG production and high plasma sex steroid values $\stackrel{0}{\frac{0}{\odot}}$ usually show suppressed follicle stimulating hormone $\stackrel{\Phi}{\oplus}$ concentrations. It has been suggested that the reason HCG secretion does not cause precocious puberty in 
girls is because ovarian follicular development depends upon stimulation by both follicle stimulating hormone and luteinising hormone.

By the end of radiotherapy there was clinical, biochemical, and radiological evidence of tumour regression. The $\beta \mathrm{HCG}$ concentration became undetectable and consequently the serum testosterone concentration fell from 28.4 to $1.7 \mathrm{nmol} / 1$ $(98.46 \mathrm{ng} / \mathrm{ml}$ to $5.89 \mathrm{ng} / \mathrm{ml})$. Within $2-3$ months the testosterone concentration rose to $10 \mathrm{nmol} / \mathrm{l}$ $(34.67 \mathrm{ng} / \mathrm{ml})$ and there was an increase in the size of the testes. Gradually over the 2 year follow up period the serum follicle stimulating hormone value rose, associated with an increase in the size of the testes from 3 to $8 \mathrm{ml}$ reflecting normal activity of the hypothalamic pituitary gonadotrophin axis.

Operative intervention in patients with pineal tumours has a high morbidity and mortality. ${ }^{\text {? }}$ Furthermore, as illustrated by our patient, the pineal germinoma is highly radiosensitive and may be cured by radiotherapy alone. ${ }^{8}$ Providing the diagnosis can be made early, and unless a shunt is required, surgery may be avoided. The $\beta$ HCG assay allows such a diagnosis to be made biochemically and we believe that this should be measured in all boys with precocious puberty.

\section{References}

1 Wass JAH, Jones AE, Rees LH, Besser GM. hCG $\beta$ producing pineal choriocarcinoma. Clin Endocrinol $(O x f) 1982 ; 17: 423-31$.

2 Romshe CA, Sotos JF. Intracranial human chorionic gonadotrophin secreting tumor with precocious puberty. J Pediatr 1975; 86: 250-2.

3 Pomarede R, Czernichow P, Finidori J, et al. Endocrine aspects and tumoral markers in intracranial germinoma: an attempt to delineate the diagnostic procedure in 14 patients. J Pediatr 1982; 101 : 374-78.

4 Sklar CA, Conte FA, Kaplan SL, Grumbach MM. Human chorionic gonadotropin-secreting pineal tumor: relation to pathogenesis and sex limitation of sexual precocity. J Clin Endocrinol Metab 1981 ; 53 : 656-9.

5 Tanner JM. Growth at adolescence. 2nd edition. Oxford: Blackwell, 1962.

6 Tanner JM, Whitehouse RH, Marshall WA, Healy MJ, Goldstein H. Assessment of skeletal maturity and prediction of adult height (TW2 method). London: Academic Press, 1975.

7 Brady LW. The role of radiation therapy. In:Schmidek HH, ed. Pineal tumours. New York: Masson Publishing, 1977: 127-32.

8 Sung DII, Harisiadis L, Chang CH. Midline pineal tumors and suprasellar germinomas: highly curable by irradiation. Radiology $1978 ; 128$ : 745-51.

Correspondence to Dr S R Ahmed, Department of Endocrinology, Christie Hospital and Holt Radium Institute, Manchester M20 9BX.

Received 15 March 1983

\section{Psychogenic cough}

\section{A SHUPER, M MUKAMEL, M MIMOUNI, M LERMAN, AND I VARSANO}

Department of Pediatrics B, Beilinson Medical Center, Tel Aviv University Medical School, Petah Tiqva, Israel

SUMMARY Psychogenic cough is croupy and explosive, never occurs during sleep, and is not affected by antitussive drugs. Physical and radiographic examinations of the respiratory tract and microbiological investigations are normal. Bronchial asthma manifested as chronic cough should be excluded in each patient by lung function testing.

Psychogenic factors are known to be a possible cause of persistent cough in children. ${ }^{1}$ In these cases the cough is very disturbing but its aetiology is generally recognised only after a long period of troublesome and expensive diagnostic procedures. The diagnostic delay is in part due to difficulties in differentiating the cough from other chronic respiratory diseases and unfamiliarity with this condition. Although 'psychogenic cough' is not rare, very few detailed descriptions are available in the published reports. ${ }^{2-5}$ We report 6 patients with psychogenic cough and review previously reported cases to alert physicians to this aetiology of cough in children.

\section{Case reports}

Case 1. An 11 year old girl was referred to our out-patient clinic because of persistent cough which had begun 6 months before. The cough was paroxysmal, harsh, barky, and non-productive. It recurred frequently during waking hours but never during sleep and distracted her from school, friends, and social activities. Her past medical history gave no clues and trials with different antibiotics, antihistamines, and antitussives were unsuccessful.

Physical examination, including direct laryngoscopy, revealed no abnormality. Repeated complete blood counts, sputum cultures, and serologic 